\title{
TEACHING OF ASTRONOMY IN INDIA: With Special Reference to Teaching of Astronomy at Lucknow University
}

\author{
P.P. Saxena \\ Department of Mathematics \& Astronomy, Lucknow University, Lucknow, India
}

\section{The Teaching of Astronomy in India}

\section{a) Introduction of modern astronomy in India}

Modern astronomy started in India when an astronomical observatory was founded in Madras as early as 1786 by the East India Company and to which the Indian Institute of Astrophysics traces its origin. There are, however, records of astronomical observations taken through a telescope from Pondicherry that elucidate the double-star nature of Alpha-Centauri as early as in 1689. Since then many more research centers in astronomy have been established. Today, institutions like the Indian Institute of Astrophysics (Bangalore), the Raman Research Institute (Bangalore), the Center of Advanced Study in Astronomy (Hyderabad), the Tata Institute of Fundamental Research (Bombay), and the Physical Research Laboratory (Ahmedabad) are engaged in pioneering work in theoretical and observational branches of astronomy and astrophysics.

\section{b) Present teaching status of astronomy in India}

At the pre-university level (grades 9 to 12): The Central Board of Secondary Education has prescribed a course of astronomy/astrophysics at the school level that is good enough to familiarize the student with the subject.

At the university level: Formal teaching of astronomy at the university level is imparted in more than two dozen universities as a part of the physics/mathematics syllabus. Facilities for imparting the teaching of astronomy as an elective subject exist in three universities, viz, for undergraduate (B.Sc.) teaching -- Lucknow University, Lucknow; for post-graduate (M.Sc.) teaching - Osmania University, Hyderabad; and for both undergraduate and postgraduate teaching - Punjabi University, Patiala. Lately, Poona ${ }^{1}$ has also been chosen for graduate teaching and research in astronomy. There exist, however, a variety of syllabi of astronomy at the various universities.

\section{c) Need for a "core" syllabus of astronomy at the university level}

Efforts must be made for uniformity in the syllabi of astronomy in mathematics and in physics and as a full elective subject at the B.Sc. and M.Sc. levels. This would have the following advantages:

\footnotetext{
${ }^{1}$ The name of the city of Poona has now been officially changed to Pune.
} 
1. It will help in maintaining a uniform standard of astronomy education.

2. In the initial stages it will be easier to train teachers in astronomy (presently there is an acute scarcity of teachers of astronomy).

3. Books may be written on this "core" syllabus to the benefit of all students of astronomy.

\section{Teaching Astronomy at Lucknow University}

\section{a) As an elective subject at the B.Sc. level}

Teaching astronomy as an elective subject at the undergraduate level started at Lucknow University as early as 1950 at the initiative taken by the then Head of the department, Professor A.N. Singh. The university offers a course in astronomy to the students who opt for astronomy, physics, and mathematics as subjects of their study at the B.Sc. level. In the third (final) year of B.Sc. studies, the number of subjects is reduced to two so that the subjects may be taught more extensively.

The number of places available is 10 . The number of students actually admitted, however, is around 60 for the last two years, partly because of the students' increased liking for the subject and partly because of the fact that Lucknow University is the only university in the state of Uttar Pradesh where astronomy is taught as an elective subject at the undergraduate level. The six-fold increase in the number of admitted students creates difficulties in laboratory classes, but it is hoped that the situation will become normal soon when we shall have more facilities available to us.

The syllabus and courses in astronomy in the three-year degree program are shown in Table 1 for each of the three years. Copies of the syllabus are available from me.

Table 1. Courses in astronomy at the B.Sc. level

(Lucknow University)

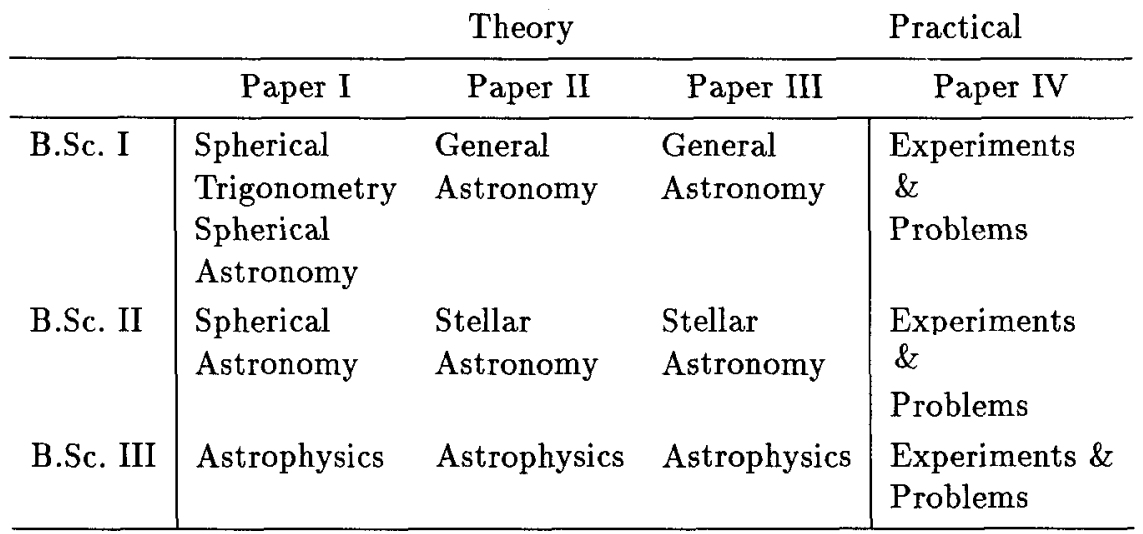


In framing the syllabus, due consideration is given to the fact that the student learns about the celestial bodies and the observed phenomena gradually. During the first year, the students' knowledge of astronomy is confined to the solar system. In the second year, this knowledge is extended to stars and stellar associations. In the third year, stress is on the physics of the observed phenomena relating to celestial bodies. The teaching hours per week are tabulated below (Table 2):

Table 2. Teaching hours per week

\begin{tabular}{ll|cc|c}
\multicolumn{2}{c}{ Class } & \multicolumn{2}{c}{ Astronomy } & Total hours/week \\
\hline & & Theory & Practical & \\
\hline B.Sc. & I & 6 & 12 & 18 \\
& II & 6 & 12 & 18 \\
III & 9 & 12 & 21 \\
\hline
\end{tabular}

b) Teaching astronomy as part of the mathematics syllabus at the M.Sc. level at Lucknow University

There is an optional paper of "Astrophysics" for the M.Sc. final-year students of mathematics. Copies of the syllabus are available from me. An average number of students opting for this paper is ten and the number of teaching hours per week is four.

\section{c) Facilities at Lucknow University}

Astronomical equipment includes a 15 -cm (6-inch) f/10 Watson refractor, a 10-cm (4-inch) f/15 Unitron telescope on an equatorial mount with a drive, four each of theodolites and sextants, a transparent star globe and a celestial globe, and a number of binoculars. The university acquired a planetarium (Spitz model) in 1951 and astronomical activities at the Department of Mathematics and Astronomy include, besides photography of the moon (which constitutes a practical at the B.Sc. level), planetarium shows, open-night shows, and astronomical film show on a regular basis. Educational tours to an observatory once every two years provide the students with an opportunity to familiarize themselves with the observational techniques used in astronomical observations.

\section{A Few Suggestions for the Development of Teaching of Astron- omy in India}

a) In India, modern astronomy started as a discipline for research much earlier than as a discipline for teaching. At the university level, the number of departments of astronomy are, therefore, extremely low at present. There is an imperative need to increase this number at the earliest possibility. 
b) There are very limited teaching facilities in astronomy in view of the acute scarcity of qualified astronomy teachers and also of equipment, which is quite expensive. A more liberal attitude for supplementing is needed.

c) Presently, astronomy seems to have limited job potential in India. The postgraduates in astronomy have no avenues for entering the teaching profession, as neither the subject nor the post of astronomy teacher exists in most of the colleges and universities. Unless they are created, there is little hope for availability of qualified staff in astronomy.

d) Astronomy books are not easily available. They should be made available at low cost.

e) Usually astronomy is mistaken for astrology. Ignorance of the subject and its importance among the general public and those who matter could be removed by educating them through the media.

\section{TEACHING ELEMENTARY ASTRONOMY IN VILLAGE PRIMARY SCHOOLS IN INDIA}

Dr. M.F. Ingham, Institute of Astronomy, University of Cambridge, U.K., reported on the work of Professor V.G. Kulkarni and his colleagues at the Homi Bhabha Centre for Science Education, none of whom could attend this meeting. They are preparing some excellent material for teaching elementary astronomy in village primary schools in India. The text of Dr. Ingham's paper was not provided to us, but we have included, below, some of the discussion which followed this interesting paper. Further information can be obtained from Professor V.G. Kulkarni, Homi Bhabha Centre for Science Education, Tata Institute for Fundamental Research, Homi Bhabha Road, Bombay 400 005, India - Editors.

\section{Discussion}

J.V. Narlikar: The Homi Bhabha Centre for Science Education gets financial support from the Sir Dorab Tata (charitable) Trust. It also gets considerable infrastructure support from the Department of Atomic Energy of the Government of India, which supports the Tata Institute for Fundamental Research.

J.L. Dunlap: Did the materials suggest the use of common objects to model the concepts presented to the children?

M.F. Ingham: The drawings, for example, for day/night, show the use of a ball and a lamp. This showed a method by which the ideas could be confirmed.

C. Iwaniszewska: How would the language (local language) problem be dealt with 